\title{
Reduced forced expiratory flow but not increased exhaled nitric oxide or airway responsiveness to methacholine characterises paediatric sickle cell airway disease
}

\author{
Rifat A Chaudry, ${ }^{1,2}$ Mark Rosenthal, ${ }^{2}$ Andrew Bush, ${ }^{2,3}$ Suzanne Crowley ${ }^{1}$
}

\begin{abstract}
- Additional material is
published online only. To view please visit the journal online (http://dx.doi.org/10.1136/ thoraxjnl-2013-204464).

${ }^{1}$ Department of Paediatrics, St George's Hospital, London, UK

${ }^{2}$ Department of Paediatric Respiratory Medicine, Royal Brompton Hospital, London, UK

${ }^{3}$ Department of Paediatrics, Imperial College, London, UK
\end{abstract}

\section{Correspondence to} Dr Suzanne Crowley, Section for Paediatric Lung and Allergic Diseases,

Oslo Universitetssykehus, Rikshospitalet, Oslo 0027, Norway;

suzcro@ous-hf.no

Received 15 September 2013 Revised 17 January 2014 Accepted 22 January 2014 Published Online First 12 February 2014

\begin{abstract}
Background Asthma and airway hyper-responsiveness are reportedly more common in children with sickle cell disease (SCD).

Aim To determine airway responsiveness, airway inflammation and clinical features of asthma in SCD. Methods A prospective, single-centre study of 50 SCD children without overt pulmonary vascular disease and 50 controls. Exhaled nitric oxide (FeNO) and total serum $\mathrm{lgE}$ were measured and spirometry and methacholine challenge were performed. The methacholine doseresponse slope (DRS) was calculated.
\end{abstract}

Results Doctor diagnosis of asthma was made in 7 (14\%) SCD versus $12(24 \%)$ control subjects $(p=0.203)$. FeNO levels were similar in SCD and controls $(p=0.250)$, and were higher in those with atopy and an asthma diagnosis (OR 4.33, 95\% Cl 1.7 to $11.1 ; p<0.05)$. $z F E V_{1}(p=0.002)$ and $z F E V_{1} / F V C(p=0.003)$ but not zFVC ( $p=0.098)$ were lower in SCD versus controls. DRS was higher in those with asthma $(p=0.006)$ but not in SCD versus controls $(p=0.403)$. DRS correlated with FeNO and blood eosinophil count in controls but not SCD. In SCD, DRS was higher in those admitted to hospital with respiratory symptoms ( $n=27)$ versus those never admitted $(n=23)(p=0.046)$. DRS was similar in those with at least one acute chest syndrome episode $(n=12)$ versus those with none $(n=35)(p=0.247)$. Conclusions SCD children have airflow obstruction despite having minimal evidence of pulmonary vascular disease. Airflow obstruction is not associated with increased methacholine sensitivity or eosinophilic inflammation, at least as judged by FeNO. Airflow obstruction in SCD does not appear to be related to childhood eosinophilic asthma, but its pathophysiology remains ill understood.

\section{INTRODUCTION}

The haemoglobinopathy sickle cell disease (SCD) is characterised by haemolytic anaemia and recurrent vascular occlusive episodes predisposing to chronic tissue ischaemia and infarction. Defective haemoglobin $(\mathrm{HbS})$ synthesis results in the polymerisation of $\mathrm{HbS}$ and sickle-shaped erythrocytes under hypoxic conditions. Patients with SCD are either homozygous for HbS (HbSS) or compound heterozygotes (HbSC), the latter probably having a lower incidence of vasculopathy. ${ }^{1}$

Respiratory morbidity, including asthma ${ }^{2}{ }^{3}$ and acute chest syndrome (ACS), ${ }^{4-6}$ is common in

\section{Key messages}

What is the key question?

- Is there an increased prevalence of asthma and airway hyper-responsiveness in children with sickle cell disease?

What is the bottom line?

- Children with sickle cell disease and only minimal evidence of pulmonary vascular disease had airflow obstruction, but no increase in airway responsiveness or exhaled nitric oxide.

\section{Why read on?}

- Airflow obstruction is an early feature of sickle cell disease, but this does not appear to be related to childhood eosinophilic asthma and should not be treated as such.

children with SCD. Elevated total IgE in SCD is associated with increased wheeze and cough and is an independent risk factor for ACS. ${ }^{7}$ Diagnosing asthma in SCD is difficult. Airway hyperresponsiveness (AHR) measured using cold air or exercise has been reported in $20-64 \%$ in children with $\mathrm{SCD}^{389}$ but is not associated with symptoms of reactive airway disease ${ }^{8}$ or ACS. ${ }^{9}$ AHR to methacholine is no more frequent in SCD children reporting asthma symptoms than unselected SCD children, ${ }^{10}{ }^{11}$ suggesting that AHR may be a component of $\mathrm{SCD}^{8}$ while asthma may represent a distinct coexisting condition. ${ }^{2}$ Ethnicity may be an important factor though, since AHR has been reported in $42 \%$ of young, healthy, AfricanAmerican children, despite a doctor diagnosis of asthma in only $10 \% .^{12}$ Exhaled nitric oxide (FeNO) levels in children with asthma are used as an indicator of eosinophilic airway inflammation, but studies in SCD children are few. FeNO has been reported as higher, ${ }^{13}$ similar $^{14}$ or lower ${ }^{15}$ in SCD patients compared with healthy controls.

Both obstructive and restrictive lung function have been described in SCD. Lower airway obstruction is reported in 13-35\% of unselected SCD children aged 3 months or above ${ }^{16-18}$ and is associated with an increased incidence of pain and chest crises. ${ }^{16}$ Others report a lower prevalence of lower 
airway obstruction and suggest that age may be an important factor, with restrictive lung function developing in older children and young adults due to previous episodes of ACS and chronic lung injury. ${ }^{19}$

We have previously compared the pulmonary vascular abnormalities in 50 SCD children with controls of a similar age, gender and ethnicity showing that SCD children had pulmonary hypertension related to increased pulmonary blood flow, ${ }^{20}$ but only subtle abnormalities of pulmonary vasculature manifest on exercise by a failure to increase carbon monoxide transfer $\left(\mathrm{D}_{\mathrm{L}} \mathrm{CO}\right.$, a surrogate for pulmonary capillary blood volume). ${ }^{21}$ We prospectively compared airway function in these two groups, hypothesising that SCD children with minimal pulmonary vascular changes may still have airflow obstruction.

\section{METHODS}

Patient selection and recruitment

Fifty (26 female) patients aged 10-18 years with known haemoglobin SS or SC disease were recruited from the paediatric haematology clinic at St George's Hospital, London, UK. Full details have been reported before. ${ }^{20}{ }^{21}$ Inclusion criteria were age $>10$ years, height $>125 \mathrm{~cm}$, genotype SS or SC and at least one Afro-Caribbean parent. Children had to be $>125 \mathrm{~cm}$ to perform bicycle exercise testing. Exclusion criteria were HIV infection or a history of cerebrovascular accident or congenital heart disease. Fifty-six consecutive patients were originally invited to participate in the study; five declined and one was excluded (HIV-positive). All participants had to be well and free of any vaso-occlusive crises (VOC) for $\geq 14$ days before investigations. Fifty ( 25 female) unselected, controls of similar age, sex and ethnicity were recruited from 59 patients' friends and siblings; nine declined and none were excluded. History, including pulmonary symptoms, and examination, including Tanner ${ }^{22}$ pubertal staging, was performed in all participants. In SCD patients, the number of hospital admissions with painful VOC in the previous 2 years and the total number of admissions with ACS were recorded. A history of doctor-diagnosed asthma was determined by asking the questions: (1) Have you ever been told by your GP that you have asthma? (2) Do you or have you used any inhaled medications for treatment of asthma? A history of atopy was sought by asking subjects and their parents whether their doctor had diagnosed eczema, hay fever or allergic rhinitis at any time. Specific features of asthma and atopy were also sought as part of the examination. Blood was taken for measurement of total $\operatorname{IgE}$, haemoglobin $(\mathrm{Hb})$, reticulocyte count, per cent fetal $\mathrm{Hb}$ and $\mathrm{Hb}$ electrophoresis. Standing height $\pm 1 \mathrm{~mm}$ was measured (Harpenden stadiometer, Holtain Ltd. Crymmych, UK) along with weight $\pm 0.1 \mathrm{~kg}$ using electronic scales (Seca, Birmingham, UK). Ethics approval was granted by Wandsworth Local Ethics Committee ref no 04/Q0803. Informed written consent was obtained for each subject.

\section{Exhaled nitric oxide}

Single-breath online FeNO measurement, in accordance with European Respiratory Society/American Thoracic Society (ERS/ ATS) guidelines, was always performed before spirometry as forced expiration may decrease FeNO. ${ }^{23}$ Details are available in the online supplement.

\section{Spirometry}

Spirometry was performed according to ATS/ERS guidelines. ${ }^{24}$ The Global Lungs Initiative (GLI) reference data were used and subjects converted to $\mathrm{z}$ scores using the GLI reference equations. ${ }^{25}$ Details are available in the online supplement.

\section{Methacholine challenge testing}

Methacholine challenge was performed according to ATS/ERS guidelines. $^{26}$ Instead of a baseline $\mathrm{FEV}_{1}<60 \%$ predicted or $<1.5 \mathrm{~L}$ as exclusion criteria, $\mathrm{FEV}_{1}<65 \%$ was used to minimise hypoxic risk. Other exclusions were current wheeze or dyspnoea or a baseline $\mathrm{SaO}_{2}$ of $<92 \%$. Heart rate and $\mathrm{SaO}_{2}$ were monitored continuously using a finger probe pulse-oximeter (Nellcor, USA). The methacholine dose-response slope (DRS) for each subject was expressed as per cent decline in $\mathrm{FEV}_{1} / \mathrm{dose}_{\text {, where }}$ the numerator was the per cent decline in $\mathrm{FEV}_{1}$ from the postsaline value to the value after the final administered dose of methacholine and the denominator was the final cumulative methacholine dose administered. ${ }^{27}$

\section{Statistical analysis}

There are no data to inform a power calculation, and sample size was opportunistic. Continuous data are presented as median and 95\% CI. Groups were compared using a Mann-Whitney test or Fisher's exact test as appropriate. Categorical variables are presented as $\mathrm{N}(\%)$, and differences were compared using $\chi^{2}$ analysis. Spearman rank correlation was used to examine the significance of the association of DRS with continuous variables. All analyses were performed using Stata V.12.1 (StataCorp LP, Texas, USA), and a $\mathrm{p}$ value of $<0.05$ was taken as being statistically significant.

\section{RESULTS}

\section{Patient characteristics and demographics}

Patients $(n=50)$ and controls $(n=50)$ were of similar age, race and gender. Patients of either sex were significantly shorter than controls (males, $\mathrm{p}=0.002$; females, $\mathrm{p}=0.021$ ) (table 1 ). SCD genotype was HbSS $(n=34)$ and HbSC $(n=16)$. Four patients were on a blood transfusion programme and two were taking hydroxyurea; of these six, one was receiving both treatments. None of the five female controls admitting to smoking cigarettes had a history of respiratory illness or asthma. None of the patients or male controls admitted to smoking.

Doctor-diagnosed asthma was not more common in SCD, occurring in 7/50 (14\%) SCD subjects and 12/50 (24\%) controls $(\mathrm{p}=0.203)$. Two controls were prescribed inhaled budesonide in doses of 200 and $400 \mu \mathrm{g} /$ day and two SCD subjects $400 \mu \mathrm{g} /$ day each. Of 27 SCD patients with previous hospital admissions for chest symptoms, 12/27 had at least one confirmed episode of ACS. Confirmed ACS occurred in 4 of 7 with doctor diagnosed asthma compared with $8 / 43$ SCD patients without asthma, $(\mathrm{p}=0.024)$.

There was no difference in total serum IgE between SCD and controls or in the prevalence of atopy, defined as total serum $\operatorname{IgE}>75 \mathrm{ku} / \mathrm{L}$. IgE was $>75 \mathrm{ku} / \mathrm{L}$ in $28 / 48$ (56\%) SCD children versus $33 / 50(64 \%)$ controls $(p=0.453$; table 1$)$.

\section{Exhaled nitric oxide}

FeNO levels in HbSS and HbSC subjects and controls were similar; HbSS 10.1 (6.9 to 13.4), HbSC 8.7 (1.9 to 15.6), controls 13.1 (10.5 to 15.8 ) ppb; $\mathrm{p}=0.250$ (figure 1 ). Twenty-two subjects ( 9 SCD, 13 controls) had FeNO $>20$ ppb; $p=0.334$. In SCD and controls combined, FeNO levels were higher in those with atopy and doctor-diagnosed asthma (OR 4.33 (1.7 to 11.1); $\mathrm{p}<0.05)$.

\section{Spirometry}

FVC $\mathrm{z}$ scores were similar in SCD subjects and controls $(p=0.098$; table 2, figure $2 \mathrm{~A})$, but $\mathrm{FEV}_{1} \mathrm{z}$ scores were lower in 
Table 1 Demographics and relevant clinical data

\begin{tabular}{|c|c|c|c|}
\hline Variables & $S C D n=50$ & Controls $n=50$ & $\mathrm{p}$ Value \\
\hline Age $^{*}$ & $14.0(13.1$ to 14.9$)$ & $15.4(14.6$ to 16.3$)$ & 0.061 \\
\hline Malet & $24(48)$ & $25(50)$ & 1.000 \\
\hline Pubertalt & $41(82)$ & $50(100)$ & 0.003 \\
\hline $\mathrm{Mt}$ & $22(92)$ & $25(100)$ & 0.235 \\
\hline $\mathrm{Ft}$ & $19(73)$ & $25(100)$ & 0.010 \\
\hline Height in $\mathrm{cm}^{*} \mathrm{M}$ & $155.0(145.9$ to 164.1$)$ & $167.0(145.9$ to 164.1$)$ & 0.002 \\
\hline $\mathrm{F}$ & 159.5 (156.0 to 163.0$)$ & 164.0 (159.8 to 168.2$)$ & 0.021 \\
\hline $\mathrm{BMI}^{*} \mathrm{M}$ & 19.2 (18.1 to 20.2$)$ & 20.8 (19.1 to 22.5$)$ & 0.019 \\
\hline $\mathrm{F}$ & 21.7 (19.2 to 24.1$)$ & 20.3 (18.5 to 22.1$)$ & 0.300 \\
\hline Haemoglobin SS† & $34(68)$ & $0(0)$ & N/A \\
\hline Haemoglobin SC $†$ & $16(32)$ & $0(0)$ & N/A \\
\hline Haemoglobin ASt & $0(0)$ & $9(18)$ & N/A \\
\hline Haemoglobin At & $0(0)$ & $41(82)$ & N/A \\
\hline $\mathrm{Hb} 8.5 \mathrm{~g} / \mathrm{dL}$ or less $t$ & $20(40)$ & $0(0)$ & $<0.001$ \\
\hline Reticulocytes $10^{9} / \mathrm{L}$ (norm $\left.25-100\right)^{*}$ & 211.5 (184.5 to 238.5$)$ & 79.0 (60.6 to 97.4$)$ & $<0.001$ \\
\hline $\mathrm{Hb} F$ \% (norm range $0-1 \%)^{*}$ & $3.6(2.1$ to 5.1$)$ & $0.2(0.1$ to 0.3$)$ & $<0.001$ \\
\hline No. on chronic transfusionst & $4(8)$ & $0(0)$ & 0.117 \\
\hline Current hydroxyurea therapy ${ }^{\dagger}$ & $2(4)$ & $0(0)$ & 0.495 \\
\hline Doctor diagnosed asthmat & 7 (14) & $12(24)$ & 0.308 \\
\hline Asthma step 3-5 BTS guidelinest & $2(4)$ & $1(2)$ & 1.000 \\
\hline No. on inhaled corticosteroidst & $2(4)$ & $5(10)$ & 0.436 \\
\hline Total IgE ku/L (norm range $0-75)^{*}$ & $90.5(0$ to 184.8$)$ & 135.0 (68.1 to 201.9$)$ & 0.453 \\
\hline
\end{tabular}

*Median and $95 \% \mathrm{Cls}$-Mann-Whitney test.

†Percentages-categorical data two-sided Fischer's exact test.

Bold type reflects statistically significant results.

N/A, not applicable; SCD, sickle cell disease.

SCD subjects compared with controls ( $p=0.002$; table 2 , figure $2 \mathrm{~B}$ ), resulting in $\mathrm{zFEV}_{1} / \mathrm{FVC}$ also being lower in SCD subjects compared with controls $(p=0.003$; figure $2 \mathrm{C}$, table 2$)$. Within the SCD group, $\mathrm{zFEV}_{1}$ and $\mathrm{zFVC}$ were lower in HbSS compared with HbSC ( $p=0.018$ and 0.004 , respectively), resulting in no difference in $\mathrm{zFEV}_{1} / \mathrm{FVC}$ between $\mathrm{HbSS}$ and $\mathrm{HbSC}$ $(\mathrm{p}=0.308$, table 3$) . \mathrm{zFEV}_{1} / \mathrm{FVC}$ in $\mathrm{SCD}$ subjects with prior admission to hospital for chest symptoms $(-0.88 \quad(-1.27$ to $-0.51), \mathrm{n}=27)$ was similar in SCD subjects with no such prior admissions (-1.07 (-1.31 to -0.47$), \mathrm{n}=23 ; \mathrm{p}=0.99)$ and similar in SCD subjects who had experienced ACS $(-0.81$ $(-1.41$ to -0.22$), \mathrm{n}=12)$ compared with those who never had $(-0.92(-1.24$ to -0.60$), \mathrm{n}=38 ; \mathrm{p}=0.75)$. Analysis of these variables excluding SCD subjects on transfusion programmes or hydroxyurea treatment $(n=5)$ did not change the significance of the results, nor did further analysis excluding smoking controls $(n=5)$ (data not shown).

\section{Methacholine challenge and sensitivity}

Ninety-three subjects completed methacholine challenge testing (MCT). Of the seven who did not, five failed to attend or refused to complete the test, $\mathrm{FEV}_{1}$ was too low $(\mathrm{n}=1)$ and $\mathrm{SaO}_{2}$ was too low $(n=1)$.

Median (95\% CI) calculated DRS was similar in SCD and control children: 0.36 (0.17 to 0.62$)$ vs 0.30 (0.20 to 0.74 ) $(p=0.403$; figure 3$)$. In all subjects, an asthma diagnosis was associated with a significantly higher DRS: 4.46 (0.27 to 6.76) vs $0.30(0.18$ to 0.36$)$ for those without asthma $(p=0.006)$. DRS correlated with $\mathrm{zFEV}_{1} / \mathrm{FVC}$, FeNO and blood eosinophil count in control but not SCD children (table 4). There was no correlation in either group between DRS and total IgE, age, $\mathrm{Hb}$ and reticulocyte count (table 4). Multiple linear regression analysis in SCD subjects with DRS as the dependent variable using

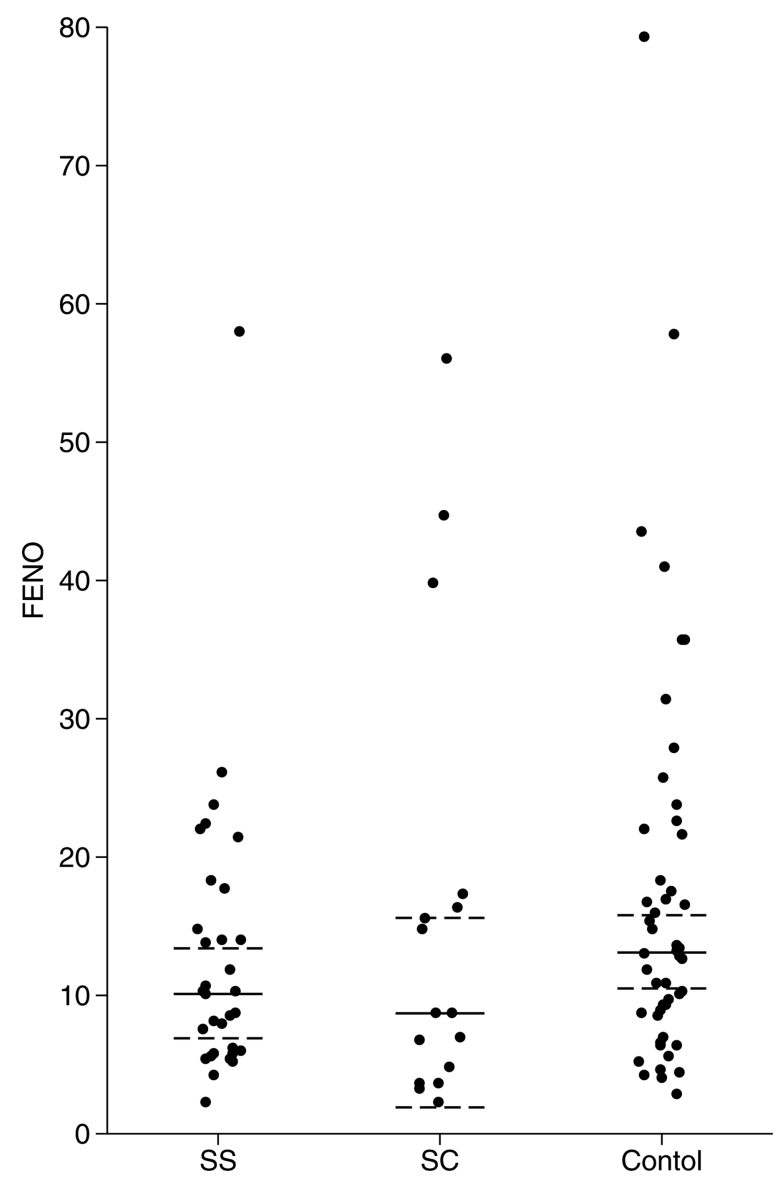

Figure 1 FeNO measurements were similar in HbSS (10.1 (6.9 to 13.4)), HbSC (8.7 (1.9 to 15.6)) and control (13.1 ppb (10.5 to 15.8)) subjects $(n=100) ; p=0.25$. 
Table 2 Spirometry in SCD patients and controls

\begin{tabular}{llll}
\hline $\begin{array}{l}\text { GLI } \\
\text { conversions* }\end{array}$ & SCD $(\mathbf{n}=50)$ & Controls $(\mathbf{n}=50)$ & $\mathbf{p}$ Value \\
\hline zFEV 1 & $-1.10(-1.38$ to -0.82$)$ & $-0.62(-1.14$ to -0.11$)$ & 0.002 \\
zFVC & $-0.62(-0.98$ to -0.26$)$ & $-0.56(-0.94$ to -0.19$)$ & 0.098 \\
zFEV $/$ FVC & $-0.95(-1.31$ to -0.58$)$ & $-0.13(-0.56$ to 0.29$)$ & $\mathbf{0 . 0 0 3}$ \\
\hline${ }^{*}$ Median $(95 \%$ Cl). & & \\
Bold type reflects statistically significant results. & \\
GLI, Global Lungs Initiative; SCD, sickle cell disease. &
\end{tabular}

age, sex, SS or SC, zFEV $1, \mathrm{zFVC} \mathrm{zFEV}_{1} / \mathrm{FVC}, \mathrm{IgE}, \mathrm{FeNO}$, VOC, ACS as independent factors showed that no factor was significant, neither together $(p=0.327)$ nor in a stepwise fashion. The same analysis in controls showed that FeNO was highly significant $(\mathrm{p}<0.001)$ explaining $28 \%$ of the variance in DRS, but no other factors were significant. Eosinophil count was not included in the regression analysis since this result was available for only $57 / 93(61 \%)$ of subjects.

There was no difference in DRS between HbSS and HbSC subjects: 0.43 (0.05 to 3.01$)$ vs $0.28(0.16$ to 3.73$)(p=0.816)$. DRS was significantly greater in those requiring admission to hospital with respiratory symptoms $(n=27)$ compared with those never admitted $(n=23): 0.44(0.23$ to 7.85$)$ vs $0.22(0.16$ to 0.65$)(p=0.046)$, while there was no difference in DRS between those who had experienced at least one episode of ACS $(n=12)$ compared with those who had not $(n=35): 0.42(0.05$ to 22.64$)$ vs $0.34(0.18$ to 0.74$)(p=0.247)$. Reanalysis of these data excluding SCD subjects on transfusion programmes or hydroxyurea treatment $(\mathrm{n}=5)$ and then excluding smoking controls $(n=5)$ made no difference to the significance of the results (data not shown).

No subject experienced significant hypoxia $\left(\mathrm{SaO}_{2}<91 \%\right)$ during MCT. Nineteen SCD patients received salbutamol following methacholine challenge, as did 18 controls. Symptoms were reported by a total of nine children (four chest tightness with wheeze, three cough only, two dyspnoea). The degree of bronchodilator reversibility was similar in SCD and controls: 33
Table 3 Spirometry in SCD subgroups

\begin{tabular}{llcl}
\hline $\begin{array}{l}\text { GLI } \\
\text { conversions* }\end{array}$ & HbSS ( $\mathbf{n = 3 4 )}$ & HbSC ( $\mathbf{n}=16)$ & $\mathbf{p}$ Value \\
\hline zFEV $_{1}$ & $-1.40(-1.81$ to 0.99$)$ & $-0.63(-1.07$ to -0.19$)$ & $\mathbf{0 . 0 1 8}$ \\
zFVC & $-0.92(-1.28$ to 0.55$)$ & $0.36(-0.16$ to 0.87$)$ & 0.004 \\
zFEV $/$ /FVC & $-0.89(-1.34$ to -0.44$)$ & $-1.01(-1.77$ to -0.25$)$ & 0.308 \\
\hline${ }^{*}$ Median (95\% Cl). & \\
Bold type reflects statistically significant results. & \\
GLI, Global Lungs Initiative; SCD, sickle cell disease.
\end{tabular}

(22 to 39$)$ vs 33 (17 to 40$) \%(p=0.796)$. No child with SCD experienced a chest crisis subsequent to MCT.

\section{DISCUSSION}

For the first time, we show that child and adolescent patients with SCD and minimal evidence of pulmonary vascular disease have reduced forced expiratory flow but no increased methacholine responsiveness or elevated FeNO compared with controls of similar age, gender and ethnicity, as might have been expected if their airway obstruction was due to asthma. The reported asthma prevalence in our controls was $24 \%$, similar to prevalence rates of $23 \%$ and $33 \%$ reported in black African and black Caribbean UK adolescents, respectively, ${ }^{28}$ and similar to the reported asthma prevalence of $14 \%$ in the SCD subjects in our study. Reported asthma prevalence may be considerably lower than AHR prevalence. Despite only $10 \%$ of non-sickle, middle-class, suburban-dwelling African-American children having an asthma diagnosis in one study, AHR prevalence was $42 \%$ and DRS did not correlate with total serum IgE. ${ }^{12}$ Other authors have reported a high prevalence of AHR in SCD children, varying from $55 \%{ }^{29}$ to $78 \%,{ }^{10}{ }^{11}$ but these studies lacked control groups for comparison. We chose to report methacholine responsiveness expressed as DRS rather than an arbitrary definition of AHR using cut-off values in order to enable the precise calculation of airway responsiveness for all subjects. ${ }^{27}$ We found that methacholine responsiveness was the same in
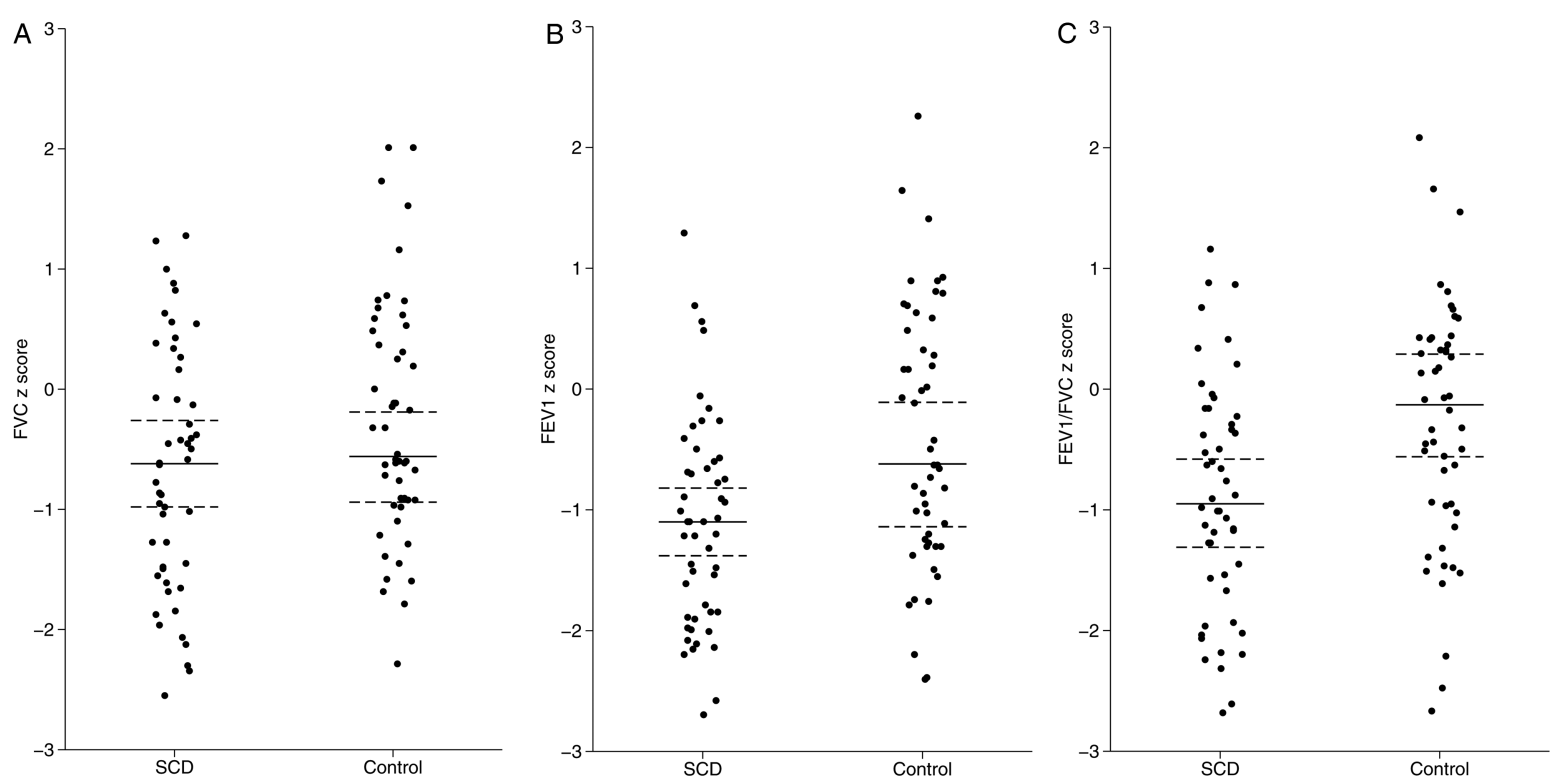

Figure 2 (A) zFVC (median, 95\% Cl) in sickle cell disease (SCD) and control subjects $(n=100) ; p=0.098$. (B) zFEV 1 (median, 95\% Cl) in SCD and control subjects $(n=100) ; p=0.002$. (C) zFEV $/$ FVC (median, $95 \%$ CI) in SCD and control subjects $(n=100) ; p=0.003$. 


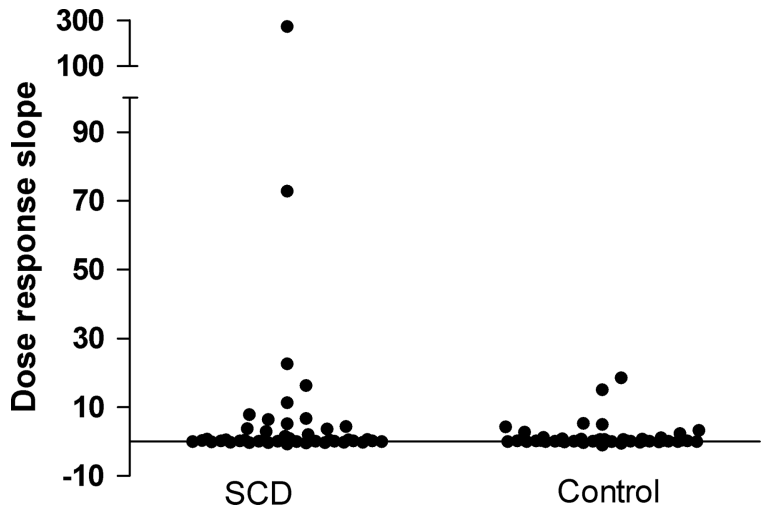

Figure 3 Dose-response slope results for all subjects ( $n=93$; $\mathrm{p}=0.403$ ).

control and SCD subjects, but was significantly increased in SCD subjects admitted to hospital for respiratory symptoms. It was not increased however in SCD subjects with at least one confirmed ACS episode, but our numbers are small. Others have reported a lack of association of AHR with ACS. ${ }^{9}$ In a different study, ${ }^{29}$ methacholine responsiveness correlated with IgE, a younger age and lactate dehydrogenase $(\mathrm{LDH})$, a marker of haemolysis. We found no such correlation with age and IgE, but we did not measure LDH. Instead, we measured reticulocyte count as an indicator of haemolysis since the usefulness of LDH as a marker of haemolysis was not established at the time of this study, but we found no correlation with methacholine responsiveness. Rather, we found correlation with markers of eosinophilic inflammation in control but not in SCD children. Additionally we found total serum IgE levels and atopy prevalence were similar in SCD and controls, but children with a reported doctor diagnosis of asthma and atopy had significantly higher FeNO, irrespective of whether or not they had SCD.

SCD subjects had significantly worse obstructive airway disease compared with controls despite similar degrees of methacholine responsiveness and asthma and atopy prevalences. Moreover, HbSS children had significantly reduced $\mathrm{zFEV}_{1}$ and zFVC compared with HbSC children despite no difference in methacholine responsiveness. Although hospital admission for respiratory symptoms was associated with increased methacholine responsiveness, it was not associated with poorer spirometry in these subjects. Similarly, spirometry was not worse in SCD subjects who had experienced ACS compared with those who had not. Methacholine responsiveness therefore may not be an important aetiological factor in the evolution of airway obstruction in SCD patients. Lower airway obstruction in SCD children becomes more prevalent with age. ${ }^{30}$ It does not seem to be associated with an asthma diagnosis but is associated with the number of chest and painful crises, ${ }^{16}$ although we did not observe this. We could not identify any clinical parameter that was associated with lower airway obstruction in SCD. We hypothesise that sickling within the bronchial circulation may lead to airway ischaemia and mucosal injury with the subsequent development of fibrosis and progressive airway obstruction. This would imply that at least some of the obstruction may be fixed. Although bronchodilator reversibility has been reported in HbSS children with lower airway obstruction, not all obstruction was reversible. ${ }^{17}$ In support of our hypothesis is the finding of generalised pulmonary inflammation, airway mucosal injury and subsequent fibrosis in patients undergoing cardiopulmonary bypass, unifocalisation procedures and lung transplantation in whom the bronchial circulation is either severely compromised or interrupted. ${ }^{31-33}$

Our study is strengthened by the inclusion of an ethnically matched control group. However, this control group is relatively small, and much larger population-based studies are needed to confirm our findings of a similar degree of airway responsiveness in healthy, black Afro-Caribbean and SCD children. The relatively low $\mathrm{zFEV}_{1}$ and $\mathrm{zFVC}$ values observed in controls may be explained by the use of GLI data that do not include ethnically adjusted prediction equations but do include reference data from this racial group. Ideally, we would have performed plethysmography to measure lung volumes, particularly functional residual capacity for evidence of air trapping and airways resistance that may have shown evidence of small airway obstruction in children with a normal $\mathrm{FEV}_{1}$. It is possible therefore that we underestimated the prevalence and degree of lower airway obstruction. The current study was part of a larger study of cardiopulmonary function in children with SCD, and in order to minimise the demands on children's time, spirometry only was performed.

Other weaknesses in our study include the relatively small numbers possibly obscuring a small increase in the prevalence of true asthma in SCD. However, we were able to show the expected elevated FeNO in atopic children, a useful positive control. We also relied on an indirect measurement of eosinophilic airway inflammation, namely FeNO, and more direct methods such as sputum induction would have been preferable. However, virtually all our patients were steroid naïve, the group in which the best agreement between FeNO and airway eosinophilia has been reported. ${ }^{34}$ Our methods would have missed any neutrophilic inflammation present, but this does not affect our conclusion that asthma medications should be used

Table 4 Associations with methacholine sensitivity expressed as DRS in SCD and control subjects

\begin{tabular}{|c|c|c|c|c|}
\hline Clinical factors & $\begin{array}{l}\text { DRS SCD } \\
\text { Spearman r }(95 \% \mathrm{Cl})\end{array}$ & $\mathrm{p}$ Value & $\begin{array}{l}\text { DRS control } \\
\text { Spearman } \mathrm{r}(95 \% \mathrm{Cl})\end{array}$ & p Value \\
\hline $\mathrm{zFEV}_{1} / \mathrm{FVC}$ & $-0.04(-0.33$ to 0.26$) ; n=46$ & 0.780 & $-0.36(-0.59$ to 0.08$) ; n=47$ & 0.012 \\
\hline FeNO & $0.25(-0.05$ to 0.5$) ; n=46$ & 0.096 & 0.33 (0.04 to 0.57$) ; n=47$ & 0.023 \\
\hline Blood eosinophil count & $0.07(-0.32$ to 0.44$) ; n=28$ & 0.708 & $0.50(0.15$ to 0.74$) ; n=29$ & 0.006 \\
\hline Total serum IgE & $-0.08(-0.04$ to 0.23$) ; n=44$ & 0.607 & $0.18(-0.12$ to 0.45$) ; n=47$ & 0.216 \\
\hline $\mathrm{Hb}$ & $-0.08(-0.36$ to 0.22$) ; n=46$ & 0.611 & $-0.03(-0.32$ to 0.27$) ; n=47$ & 0.837 \\
\hline Reticulocytes & $0.09(-0.22$ to 0.39$) ; n=42$ & 0.548 & $0.28(-0.03$ to 0.54$) ; n=44$ & 0.069 \\
\hline Age & $-0.09(-0.37$ to 0.21$) ; n=46$ & 0.556 & $-0.17(-0.44$ to 0.13$) ; n=47$ & 0.251 \\
\hline
\end{tabular}

Bold type reflects statistically significant results.

DRS, dose-response slope; SCD, sickle cell disease. 
cautiously in these patients because neutrophilic inflammation is generally not steroid sensitive. We have shown that MCT can be performed safely in children with SCD, but our relatively small numbers may have underestimated the risks. A previous study of methacholine responsiveness in 99 SCD children was complicated by a painful episode requiring hospital admission in one child. ${ }^{29} \mathrm{We}$ may have overestimated the prevalence of atopy in control and SCD children by using an arbitrary cut-off value for total serum IgE. Total IgE increases with age and there are ethnic differences, such that total IgE is approximately 1.3 times higher in Afro-Caribbean compared with white British children. ${ }^{35}$ These reference data however were derived from a study of 58 Afro-Caribbean children, and larger population-based studies are needed.

In summary, children with SCD and minimal changes of pulmonary vascular disease had evidence of airflow obstruction but without the signature features of childhood asthma, namely atopy, increased airway responsiveness to methacholine and elevated FeNO. MCT revealed that increased methacholine responsiveness in SCD children and controls was associated with a doctor diagnosis of asthma. A diagnosis of asthma and atopy was equally common in SCD and controls and was associated with higher FeNO. Our findings suggest that the similar degrees of methacholine responsiveness in SCD and controls may be related to Afro-Caribbean ethnicity rather than SCD, but this finding needs confirmation in a larger study. The implications of this study are that airway obstruction is an early feature of HbSS and HbSC SCD and is not related to asthma-like pathology. Careful consideration should be given before prescribing conventional asthma treatment in these children.

Acknowledgements L Perry and J Jaye (respiratory technicians at Royal Brompton Hospital) assisted with $10 \%$ of all airway studies. M Roughton, medical statistician, assisted with statistical analyses.

Contributors RAC recruited all subjects, supervised $90 \%$ of all tests and wrote the first draft of the paper. MR and $A B$ assisted with writing and project supervision. RAC, MR and SC analysed the data. SC designed the whole study, completed writing and supervised the project. All authors agreed on the final version of the manuscript.

Funding Sobell Institute and St George's Hospital Charitable trust.

Competing interests None.

Ethics approval Wandsworth Local Ethics Committee ref no 04/Q0803.

Provenance and peer review Not commissioned; externally peer reviewed.

\section{REFERENCES}

1 Lionnet F, Hammoudi N, Stojanovic NS, et al. Hemoglobin SC complications: a clinical study of 179 cases. Haematologica 2012;97:1136-41.

2 Ross JG, Bernaudin F, Strunk RC, et al. Asthma is a distinct comorbid condition in children with elevated total and allergen-specific IgE levels. J Ped Hem Oncol 2011;33:205-8.

3 Knight-Madden JM, Forrester TS, Lewis NA, et al. Asthma in children with sickle cell disease and its association with acute chest syndrome. Thorax 2005;60:206-10.

4 Castro O, Brambilla DJ, Thorington B, et al. The acute chest syndrome in sickle cell disease: incidence and risk factors. The Cooperative Study of Sickle Cell Disease. Blood 1994;84:643-9.

5 Vichinsky EP, Neumayr LD, Earles AN, et al. Causes and outcomes of the acute chest syndrome in sickle cell disease. National Acute Chest Syndrome Study Group. N Engl J Med 2000;342:1855-65.

6 Gladwin MT, Rodgers GP. Pathogenesis and treatment of acute chest syndrome of sickle-cell anaemia. Lancet 2000;355:1476-8.

7 An P, Barron-Casella EA, Strunk RC, et al. Elevation of IgE in children with sickle cell disease is associated with doctor diagnosis of asthma and increased morbidity. J Allergy Clin Immunol 2011;127:1440-6.
8 Leong MA, Dampier C, Varlotta L, et al. Airway hyperreactivity in children with sickle cell disease. J Pediatr 1997;131:278-83.

9 Sylvester KP, Patey RA, Rafferty GF, et al. Airway hyperresponsiveness and acute chest syndrome in children with sickle cell anemia. Pediatr Pulmonol 2007:42:272-6.

10 Strunk RC, Brown MS, Boyd JH, et al. Methacholine challenge in children with sickle cell disease: A case series. Pediatr Pulmonol 2008;43:942-9.

11 Ozbek OY, Malbora B, Sen N, et al. Airway hyperreactivity detected by methacholine challenge in children with sickle cell disease. Pediatr Pulmonol 2007:42:1187-92.

12 Joseph CL, Ownby DR, Peterson EL, et al. Racial differences in physiologic parameters related to asthma among middle-class children. Chest 2000;117:1336-44.

13 Radhakrishnan DK, Bendiak GN, Mateos-Corral D, et al. Lower airway nitric oxide is increased in children with sickle cell disease. J Pediatr 2012;160:93-7.

14 Sullivan KJ, Kissoon N, Sandler E, et al. Effect of oral arginine supplementation on exhaled nitric oxide concentration in sickle cell anemia and acute chest syndrome. J Pediatr Hematol Oncol 2010:32:249-58.

15 Girgis RE, Qureshi MA, Abrams J, et al. Decreased exhaled nitric oxide in sickle cell disease: relationship with chronic lung involvement. Am J Hematol 2003:72:177-84.

16 Boyd JH, DeBaun MR, Morgan WJ, et al. Lower airway obstruction is associated with increased morbidity in children with sickle cell disease. Pediatr Pulmonol 2009;44:290-6.

17 Koumbourlis AC, Zar HJ, Hurlet-Jensen A, et al. Prevalence and reversibility of lower airway obstruction in children with sickle cell disease. J Pediatr 2001; 138:188-12.

18 Koumbourlis AC, Hurlet-Jensen A, Bye MR. Lung function in infants with sickle cell disease. Pediatr Pulmonol 1997;24:277-81.

19 Maclean JE, Atenafu E, Kirby-Allen M, et al. Longitudinal decline in lung volume in a population of children with sickle cell disease. Am J Respir Crit Care Med 2008:178:1055-9.

20 Chaudry RA, Cikes M, Karu T, et al. Paediatric sickle cell disease: pulmonary hypertension but normal vascular resistance. Arch Dis Child 2011:96:131-6.

21 Chaudry RA, Bush A, Rosenthal $M$, et al. The impact of sickle cell disease on exercise capacity in children. Chest 2013;143:478-84.

22 Tanner JM, Davies PS. Clinical longitudinal standards for height and height velocity for North American children. J Pediatr 1985;107:317-29.

23 Baraldi E, de Jongste JC; European Respiratory Society/American Thoracic Society (ERS/ATS) Task Force. Measurement of exhaled nitric oxide in children. Eur Respir J 2002;20:223-37.

24 Laszlo G. Standardisation of lung function testing: helpful guidance from the ATS/ ERS Task Force. Thorax 2006;61:744-46.

25 Quanjer PH, Stanojevic S, Cole TJ, et al. Multi-ethnic reference values for spirometry for the 3-95 year age range: the global lung function 2012 equations. Eur Respir J 2012;40:1324-43.

26 Crapo RO, Casaburi R, Coates AL, et al. Guidelines for methacholine and exercise challenge testing. Am J Respir Crit Care Med 2000;161:309-29.

27 O'Connor C, Sparrow D, Taylor D, et al. Analysis of dose-response curves to methacholine. An approach suitable for population studies. Am Rev Respir Dis 1987;136:1412-17.

28 Whitrow M, Harding S. Asthma in Black African, Black Caribbean and South Asian adolescents in the MRC DASH study: a cross sectional analysis. BMC Pediatrics 2010;10:18.

29 Field JJ, Stocks J, Kirkham FJ, et al. Airway hyperresponsiveness in children with sickle cell anemia. Chest 2011;139:563-8.

30 Koumbourlis $A C$, Lee $D J$, Lee $A$. Longitudinal changes in lung function and somatic growth in children with sickle cell disease. Pediatr Pulmonol 2007: 42:483-8.

31 Schulze-Neick I, Ho Y, Bush A, et al. Severe airflow limitation after the unifocalization procedure: clinical and morphological correlates. Circulation 2000;102(19 Suppl 3):III142-7.

32 Dhillon GS, Zamora MR, Roos JE, et al. Lung transplant airway hypoxia. A diathesis to fibrosis? Am J Respir Crit Care Med 2010;182:230-36.

33 Schlensak C, Doenst T, Preußer S, et al. Cardiopulmonary bypass reduction of bronchial blood flow: A potential mechanism for lung injury in a neonatal pig model. J Thorac Cardiovasc Surg 2002;123:1199-205.

34 Piacentini GL, Bodini A, Costella S, et al. Exhaled nitric oxide and sputum eosinophil markers of inflammation in asthmatic children. Eur Respir $J$ 1999;13:1386-9.

35 Chan $E Y$, McKenzie SA. Normative data for total serum immunoglobulin $\mathrm{E}$ measurements in children of three ethnicities. Clin Exp Allergy 2003;33:752-6. 